\title{
Analisis Potensi Interaksi Obat Golongan Antidepresan pada Pasien Skizofrenia di Rumah Sakit Jiwa Dr. Soeharto Heerdjan Tahun 2016
}

\section{Analysis of Potential Antidepressant Drug Interactions in Schizophrenic Patients at Dr. Soeharto Heerdjan 2016}

\author{
Atika Wahyu Puspitasari", Loranda Angeline \\ Fakultas Farmasi, Universitas Indonesia, Depok, Indonesia
}

\begin{abstract}
ABSTRAK
Pasien skizofrenia yang menggunakan terapi obat kombinasi antidepresan dalam pengobatannya dapat menimbulkan interaksi obat. Penelitian ini bertujuan untuk mengetahui potensi interaksi obat golongan antidepresan pada pasien skizofrenia. Desain penelitian ini menggunakan cross sectional. Data yang digunakan adalah data sekunder dari resep dan rekam medis pasien skizofrenia rawat jalan di RSJ Dr. Soeharto Heerdjan tahun 2016 dengan metode retrospektif. Pengambilan sampel dilakukan secara acak. Data sampel yang dianalisis sebanyak 743 lembar resep dan sebanyak 694 $(91,41 \%)$ lembar resep terdapat interaksi obat dengan jumlah kasus interaksi sebanyak 1286 kasus $(61,24 \%)$. Jenis interaksi obat yang paling banyak ditemukan adalah fluoksetin dan risperidon sebanyak 376 kasus $(29,24 \%)$. Tingkat keparahan interaksi mayor sebanyak 1246 kasus $(96,89 \%)$, moderat sebanyak 34 kasus $(2,64 \%)$ dan minor sebanyak 6 kasus $(0,47 \%)$. Tingginya kejadian interaksi obat pada peresepan antidepresan memerlukan pemantauan yang ketat, dan bila perlu dimodifikasi ketika dampak negatif yang ditimbulkan lebih besar daripada dampak positif.
\end{abstract}

Received: July 2018

Revised: August 2018

Accepted: December 2018

Kata kunci : antidepresan; interaksi obat; skizofrenia; rumah sakit; rawat jalan

\begin{abstract}
Schizophrenic patients who used antidepressant combination drug therapy in their treatment can cause drug interaction. This study aimed to determine the potential drug interactions of antidepressant in schizophrenic patients. The study designed was cross-sectional by random sampling. The samples were secondary data from outpatient prescriptions and medical record of schizophrenic patients in Psychiatric Hospital Dr. Soeharto Heerdjan during 2016. From 743 drug prescriptions, it was found that 694 (91.41\%) drug prescriptions having 1286 (61.24\%) cases of drug interaction. The most common interaction were fluoxetine and risperidone in 376 cases $(29.24 \%)$. The proportion based on interaction level was 1246 cases $(96.89 \%)$ for severe, 34 cases $(2.64 \%)$ for moderate, and 6 cases $(0.47 \%)$ for minor. The study concluded that antidepressant prescribing needs to be closely monitored because of high incidence in drug interactions or modified when the negative impact was greater than the positive impact.
\end{abstract}

*corresponding author

Keywords: antidepressant; drug interaction; schizophrenia; hospital; outpatient

Email: atikawahyu@farmasi.ui.ac.id

\section{PENDAHULUAN}

Kesehatan jiwa saat ini merupakan salah satu permasalahan kesehatan yang menjadi perhatian utama di dunia. Depresi, gangguan bipolar, skizofrenia dan demensia merupakan prevalensi gangguan jiwa terbesar dari 10 masalah kesehatan yang menimbulkan disabilitas (World Health Organization, 2016). Gangguan jiwa yang menjadi salah satu masalah di negara berkembang seperti Indonesia adalah skizofrenia. Menurut data WHO (2016), terdapat sekitar 21 juta orang di duia terkena skizofrenia. Menurut Hasil Riset Kesehatan Dasar tahun 2013 di Indonesia prevalensi gangguan jiwa berat seperti skizofrenia adalah $0,17 \%$ penduduk atau sekitar 400.000 jiwa (Kementerian Kesehatan RI, 2016).

Terapi utama yang diberikan kepada pasien skizofrenia adalah antipsikotik dan antidepresan (Wells et al.,
2015). Kombinasi terapi ini bermanfaat tidak hanya mengobati gejala positif dan gejala negatif yang terjadi pada pasien skizofrenia tetapi juga dapat meningkatkan fungsionalitas dan kualitas hidup pada individu dengan skizofrenia. Akan tetapi, terapi kombinasi antidepresan berpotensi dapat menimbulkan adanya interaksi obat (Redayani, 2015; Katona et al., 2012). Interaksi obat yang dihasilkan dapat bersifat menguntungkan maupun merugikan bagi pasien (Amir, 2015). Menurut Pacer dan Valeria (2008) interaksi obat dalam penggunaan kombinasi antidepresan dan antipsikotik dapat menyebabkan aritmia jantung yang mengancam jiwa karena obat antidepresan menghambat sistem kardiovaskular. Selain itu, penelitian yang dilakukan oleh Fitriana dan Nurul (2015) tentang Potensi Interaksi Obat Antidepresan di RSJ "X" Jawa Tengah dengan menggunakan aplikasi drugs.com menunjukkan tingkat keparahan interaksi obat dengan dampak minor sebesar 
$0,61 \%$, potensi interaksi signifikan sebesar 58,18\% dan berpotensi interaksi serius sebesar $41,21 \%$.

Rumah Sakit Jiwa Dr. Soeharto Heerdjan merupakan Rumah Sakit Khusus gangguan jiwa yang terdapat di Jakarta sekaligus merupakan rumah sakit jiwa rujukan nasional. Pada tahun 2016, prevalensi tertinggi adalah skizofrenia dengan persentase $60 \%$. Hal ini mendorong peneliti untuk mengetahui potensi interaksi obat antidepresan pada pasien skizofrenia di RSJ Dr. Soeharto Heerdjan dan penelitian ini belum pernah dilakukan sebelumnya. Penelitian ini perlu dilakukan bertujuan untuk mengetahui potensi interaksi obat golongan antidepresan pada pasien skizofrenia di RSJ Dr. Soeharto Heerdjan.

\section{METODE}

\section{Desain Penelitian}

Penelitian ini bersifat deskriptif dengan desain potong lintang (cross-sectional). Pengambilan data dilakukan secara retrospektif menggunakan data sekunder yang diperoleh dari rekam medis dan resep pasien skizofrenia pada bulan Januari-Desember 2016 di RSJ Dr. Soeharto Heerdjan, Jakarta Barat. Populasi penelitian adalah semua lembar resep pasien rawat jalan yang mendapatkan obat antidepresan di RSJ Dr. Soeharto Heerdjan pada tahun 2016. Sampel penelitian adalah semua lembar resep pasien skizofrenia rawat jalan yang yang mendapatkan terapi kombinasi obat antidepresan di RSJ Dr. Soeharto Heerdjan pada tahun 2016. Teknik pengambilan sampel menggunakan metode random sampling.

Jumlah sampel dihitung dengan rumus Slovin:

$$
n=\frac{N}{1+N(d)^{2}}
$$

Keterangan :

$\mathrm{n}=$ jumlah sampel

$\mathrm{N}=$ jumlah populasi

$\mathrm{d}=$ tingkat ketepatan absolut yang dikehendaki $10 \%(0,10)$
Populasi penelitian yang digunakan berdasarkan jumlah resep pasien yang mendapatkan antidepresan setiap bulannya.

$$
n=\frac{N}{1+N(d)^{2}}=\frac{127}{1+127(d)^{2}}=55 \text { lembar resep }
$$

Perhitungan pengambilan sampel penelitian di atas merupakan contoh perhitungan pengambilan sampel pada bulan Januari 2016 dengan populasi sebanyak 127 lembar resep, sehingga diperoleh sampel 55 lembar resep. Perhitungan tersebut akan digunakan untuk menentukan sampel pada bulan berikutnya dengan populasi yang berbeda. Total sampel yang akan digunakan sebanyak 743 lembar resep.

Kriteria inklusi penelitian ini adalah lembar resep pasien skizofrenia rawat jalan berusia $\geq 18$ tahun yang mendapatkan minimal 2 obat yang salah satunya adalah obat golongan antidepresan dan lembar resep pasien BPJS rawat jalan yang berobat di RSJ Dr. Soeharto Heerdjan pada tahun 2016. Sedangkan kriteria eksklusi adalah lembar resep yang tidak lengkap dan tidak terbaca dengan jelas. Sampel yang memenuhi kriteria inklusi akan dicatat data penggunaan obat pasien per lembar resep dan dianalisis interaksi obatnya berdasarkan tingkat keparahannya dengan perangkat lunak Micromedex Drug Interaction Checker.

\section{HASIL DAN PEMBAHASAN}

\section{Pola Peresepan}

Golongan obat antidepresan yang diresepkan pada pasien skizofrenia di RSJ Dr. Soeharto Heerdjan pada tahun 2016 dapat dilihat pada Tabel 1. Golongan obat antidepresan yang sering diresepkan adalah Selective Serotonin Reuptake Inhibitor (SSRI) dengan persentase 98,79\%. Golongan SSRI merupakan antidepresan lini pertama dan generasi baru. Efek samping dan toksisitas yang ditimbulkan SSRI lebih rendah dibandingkan golongan antidepresan lainnya. Efek sedatif, antikolinergik dan efek yang tidak diinginkan terhadap kardiovaskular lebih rendah dibandingkan golongan lain. Selain itu, obat ini juga tidak memberikan efek samping terhadap kenaikan berat badan (Wells et al., 2015).

Tabel 1. Jenis obat antidepresan yang diresepkan

\begin{tabular}{lll}
\hline Jenis Obat Antidepresan & Jumlah & Persentase (\%) \\
\hline SSRI & $\mathbf{7 3 8}$ & $\mathbf{9 8 , 7 9}$ \\
Fluoksetin & 616 & 82,46 \\
Sertralin & 119 & 15,93 \\
Escitalopram & 3 & 0,40 \\
TCA & $\mathbf{9}$ & $\mathbf{1 , 2 1}$ \\
Amitriptilin & 9 & 1,21 \\
\hline
\end{tabular}


Tabel 2. Jenis kombinasi obat antidepresan

\begin{tabular}{|c|c|c|}
\hline Jenis Kombinasi & Jumlah Kombinasi & Persentase (\%) \\
\hline Fluoksetin - triheksifenidil & 441 & 21,00 \\
\hline Fluoksetin - risperidon & 374 & 17,81 \\
\hline Fluoksetin - klozapin & 346 & 16,48 \\
\hline Fluoksetin - olanzapin & 150 & 7,14 \\
\hline Fluoksetin - seroquel & 110 & 5,24 \\
\hline Sertralin - triheksifenidil & 68 & 3,24 \\
\hline Sertralin - klozapin & 60 & 2,86 \\
\hline Fluoksetin - depakote & 59 & 2,81 \\
\hline Fluoksetin - lorazepam & 59 & 2,81 \\
\hline Fluoksetin - flufenazine & 45 & 2,14 \\
\hline Sertralin - risperidon & 42 & 2,00 \\
\hline Fluoksetin - trifluoperazin & 37 & 1,76 \\
\hline Sertralin - seroquel & 37 & 1,76 \\
\hline Sertralin - olanzapin & 36 & 1,71 \\
\hline Fluoksetin - klorpromazin & 24 & 1,14 \\
\hline Fluoksetin - neurodex & 19 & 0,90 \\
\hline Fluoksetin - aripiprazol & 17 & 0,81 \\
\hline Fluoksetin - donepezil & 13 & 0,62 \\
\hline Fluoksetin - klobazam & 11 & 0,52 \\
\hline Sertralin - klobazam & 11 & 0,52 \\
\hline Fluoksetin - haloperidol & 10 & 0,48 \\
\hline Sertralin - flufenazin & 9 & 0,43 \\
\hline Sertralin - depakot & 8 & 0,38 \\
\hline Sertralin - lorazepam & 8 & 0,38 \\
\hline Fluoksetin - alprazolam & 7 & 0,33 \\
\hline Sertralin - alprazolam & 7 & 0,33 \\
\hline Amitriptilin - triheksifenidil & 6 & 0,29 \\
\hline Fluoksetin - diazepam & 6 & 0,29 \\
\hline Sertralin - klorpromazin & 6 & 0,29 \\
\hline Amitriptilin - risperidon & 5 & 0,24 \\
\hline Fluoksetin - kurkuma & 4 & 0,19 \\
\hline Fluoksetin - lesicol & 4 & 0,19 \\
\hline Sertralin - aripiprazol & 4 & 0,19 \\
\hline Amitriptilin - klozapin & 3 & 0,14 \\
\hline Amitriptilin - fluoksetin & 3 & 0,14 \\
\hline Amitriptilin - trifluoperazin & 3 & 0,14 \\
\hline Fluoksetin - ikalep & 3 & 0,14 \\
\hline Fluoksetin - klonazepam & 3 & 0,14 \\
\hline Fluoksetin - mersibion & 3 & 0,14 \\
\hline Sertralin - trifluoperazin & 3 & 0,14 \\
\hline Amitriptilin - alprazolam & 2 & 0,10 \\
\hline Escitalopram - fluoksetin & 2 & 0,10 \\
\hline
\end{tabular}


Tabel 2. Jenis kombinasi obat antidepresan (lanjutan)

\begin{tabular}{lll}
\hline Jenis Kombinasi & Jumlah Kombinasi & Persentase (\%) \\
\hline Escitalopram - klozapin & 2 & 0,10 \\
Escitalopram - risperidon & 2 & 0,10 \\
Escitalopram - triheksifenidil & 2 & 0,10 \\
Fluoksetin - ketokonazol & 2 & 0,10 \\
Sertralin - asam Folat & 2 & 0,10 \\
Sertralin - donepezil & 2 & 0,10 \\
Sertralin - ikalep & 2 & 0,10 \\
Amitriptilin - depakote & 1 & 0,05 \\
Amitriptilin - haloperidol & 1 & 0,05 \\
Amitriptilin - olanzapine & 1 & 0,05 \\
Escitalopram - alprazolam & 1 & 0,05 \\
Escitalopram - klobazam & 1 & 0,05 \\
Escitalopram - seroquel & 1 & 0,05 \\
Fluoksetin - antasida & 1 & 0,05 \\
Fluoksetin - asam. Folat & 1 & 0,05 \\
Fluoksetin - asam.mefenamat & 1 & 0,05 \\
Fluoksetin - fenitoin & 1 & 0,05 \\
Sertralin - diazepam & 1 & 0,05 \\
Sertralin - escitalopram & 1 & 0,05 \\
Sertralin - ibuprofen & 1 & 0,05 \\
Sertralin - kaptopril & 1 & 0,05 \\
Sertralin - klonazepam & 1 & 0,05 \\
Sertralin - kloramfenikol & 1 & 0,05 \\
\hline Total & 2100 & 100 \\
\hline & & \\
& 1 & \\
\hline
\end{tabular}

Jenis obat antidepresan golongan SSRI yang paling banyak diresepkan adalah fluoksetin dengan persentase $82,46 \%$. Fluoksetin memberikan profil keamanan dan efikasi yang paling baik untuk mengobati gejala negatif dibandingkan antidepresan jenis lain. Selain itu, pemberian fluoksetin juga meningkatkan kepatuhan pasien dalam minum obat. Penggunaan fluoksetin pada pasien usia lanjut dan wanita hamil juga lebih aman dan efektif. Di samping itu, penggunaan fluoksetin juga tidak dikaitkan dengan peningkatan resiko bunuh diri pasien pada keseluruhan evaluasi uji klinik terkontrol (Mao \& Zhang, 2015; Wagner, 2012; Rossi et al., 2004).

Peresepan kombinasi obat antidrepresan dengan obat lainnya pada pasien skizofrenia di RSJ Dr. Soeharto Heerdjan pada tahun 2016 dapat dilihat pada Tabel 2. Kombinasi yang paling banyak diresepkan adalah fluoksetin dan triheksifenidil sebanyak 441 kasus (21\%). Triheksifenidil merupakan golongan obat antikolinergik yang diindikasikan untuk meringankan gejala esktrapiramidal yang ditimbulkan golongan antipsikotik. Efek samping yang ditimbulkan akibat kombinasi obat pada pasien skizofrenia, seperti sindrom parkinsonisme, distonia, akatisia, diskinesia dapat diatasi dengan penggunaan antikolinergik, seperti triheksifenidil (Rianti et al., 2015).

\section{Gambaran Interaksi Obat}

Lembar resep obat yang memenuhi kriteria inklusi dalam penelitian ini sebanyak 743 lembar. Data penggunaan obat per lembar resep tersebut dianalisis interaksi obatnya berdasarkan tingkat keparahannya dengan menggunakan perangkat lunak Micromedex Drug Interaction Checker. Hasil analisis tersebut menyatakan bahwa sebanyak 694 lembar resep tersebut berinteraksi $(93,41 \%)$. Distribusi jumlah interaksi obat per lembar resep dapat dilihat pada Tabel 3.

Sebanyak 694 lembar resep obat yang berinteraksi ditemukan 1286 kasus interaksi obat dengan tingkat keparahan interaksi mayor, moderat, dan minor. Interaksi obat dengan tingkat keparahan mayor sebanyak 
Tabel 3. Distribusi jumlah interaksi obat per lembar resep

\begin{tabular}{lll}
\hline Kategori Resep Antidepresan & Jumlah lembar Resep & Persentase ( \%) \\
\hline Berinteraksi & 694 & 93,41 \\
Tidak ada Interaksi & 49 & 6,59 \\
\hline Total & 743 & 100 \\
\hline
\end{tabular}

1246 kasus $(96,89 \%)$ dan moderat sebanyak 34 kasus (2,64\%). Data kasus interaksi obat berdasarkan tingkat keparahannya dapat dilihat selengkapnya pada Tabel 4.

Interaksi obat dengan tingkat keparahan mayor didominasi oleh interaksi antara fluoksetin dengan risperidon sebanyak 376 kasus (29,24\%). Fluoksetin sebagai lini pertama terapi antidepresan dan risperidon sebagai antipsikotik atipikal yang memiliki harga terjangkau, efikasi dan manfaat yang lebih baik dalam mengatasi gejala positif dibandingkan antipsikotik tipikal menjadi pilihan terapi kombinasi yang sering digunakan. Penggunaan bersama fluoksetin dengan risperidon dapat meningkatkan konsentrasi risperidon karena fluoksetin menghambat enzim CYP2D6 yang bertangggung jawab dalam metabolisme risperidon melalui penghambatan jalur hidroksilasi sehingga mengurangi klirens risperidon (Spina et al., 2002). Dengan demikian, pemantauan kadar risperidon dalam plasma atau efek farmakologi yang dihasilkan dan monitoring efek samping risperidon perlu dilakukan jika kedua obat tersebut diresepkan agar toksisitas risperidon dapat dihindari. Pasien disarankan untuk menghubungi dokter jika gejala ekstrapiramidal semakin dirasakan, seperti tremor, kekakuan lidah, kejang atau kekakuan otot dan pergerakan yang tidak disadari. Selain itu, penyesuaian dosis juga dapat dilakukan jika diperlukan. Pada pasien yang mengalami akatisia dan gejala Parkinson, penambahan obat antikolinergik mungkin dapat dipertimbangkan (Brown, 2008).

Interaksi obat dengan tingkat keparahan moderat ditemukan dalam 5 kasus interaksi obat dengan peresepan terbanyak antara obat fluoksetin dengan klobazam, yaitu sebanyak 11 kasus (0,87\%). Menurut Moore, et al., (2007) penggunaan golongan benzodiazepin pada peresepan pasien skizofrenia bermanfaat mengurangi tingkat ansietas dan insomnia. Mekanisme interaksi obat fluoksetin dengan klobazam dapat meningkatkan konsentrasi plasma fluoksetin. Hal ini disebabkan klobazam dapat menghambat enzim CYP2D6 yang berperan dalam memetabolisme fluoksetin. Jika terapi kombinasi ini diperlukan, maka dosis fluoksetin harus diturunkan. Monitoring efek samping juga perlu dilakukan dan pasien perlu diinformasikan untuk menghubungi dokter atau apoteker jika efek samping berupa kesulitan bernafas, gangguan koordinasi, konfusi, rasa lelah berlebih, sedasi, dan produksi air liur berlebih timbul.
Hubungan Interaksi Obat dengan berbagai Faktor Hubungan interaksi obat dengan faktor jenis kelamin, usia, jumlah obat dan penyakit penyerta lain dianalisis dengan menggunakan Uji Kai Kuadrat. Tabel 5 menunjukan hasil analisis hubungan antara kejadian potensi interaksi dengan beberapa faktor seperti jenis kelamin, usia, jumlah obat dan penyakit penyerta.

Hasil analisis hubungan antara jenis kelamin dengan potensi interaksi obat diperoleh nilai $\mathrm{p}=0,184$. Hal ini menunjukkan bahwa faktor jenis kelamin tidak berhubungan dengan potensi interaksi obat. Hasil penelitian ini sesuai dengan penelitian yang dilakukan Sari (2015) yang menunjukkan tidak adanya hubungan antara jenis kelamin dengan potensi interaksi obat dapat disebabkan oleh tidak adanya perbedaan jenis obat yang diterima antara pasien laki-laki dan perempuan karena keduanya mendapat jenis obat yang sama.

Hasil analisis hubungan antara usia dengan potensi interaksi obat diperoleh nilai $\mathrm{p}=0,768$ sehingga menunjukkan faktor usia juga tidak berhubungan dengan potensi interaksi obat. Hal ini disebabkan karena pasien mendapatkan terapi yang sama meskipun usia pasien tersebut berbeda. Hasil penelitian tersebut bertentangan dengan penelitian yang dilakukan oleh Sari (2015) yang menyatakan ada hubungan antara usia dengan potensi interaksi obat (nilai $\mathrm{p}=0,031$ ). Pada penelitian yang dilakukan oleh Sari, sampel penelitian didominasi oleh pasien usia lanjut. Pada pasien usia lanjut interaksi obat yang terjadi kemungkinan merupakan interaksi farmakodiamik, seperti perubahan pada saluran cerna yang diduga mempengaruhi proses absorbsi obat, misalnya meningkatnya $\mathrm{pH}$ lambung, menurunnya aliran darah ke usus akibat penurunan curah jantung dan perubahan waktu pengosongan lambung dan gerak saluran cerna (Sari, 2015).

Hasil analisis hubungan antara jumlah obat dengan potensi interaksi obat diperoleh nilai $\mathrm{p}=0,000$ sehingga menunjukkan bahwa faktor jumlah obat berhubungan dengan potensi interaksi obat. Hasil tersebut sesuai dengan penelitian yang dilakukan Churi et al.(2011) yang menyatakan adanya hubungan yang bermakna antara potensi interaksi obat dengan jumlah obat yang diresepkan (nilai p < 0.01) (Churi, et al., 2011). Hal ini disebabkan semakin meningkatnya jumlah obat yang diresepkan maka potensi interaksi obat mungkin meningkat (Dasopang et al., 2015). 
Tabel 4. Kasus Interaksi obat yang teridentifikasi ( $\mathrm{N}=1286$ )

\begin{tabular}{|c|c|c|}
\hline Tingkat Keparahan & Kejadian & Persentase $(\%)$ \\
\hline Interaksi Kontraindikasi & $\mathbf{0}$ & $\mathbf{0}$ \\
\hline Interaksi Mayor & 1246 & 96.89 \\
\hline Fluoksetin - risperidon & 376 & 29.24 \\
\hline Fluoksetin - klozapin & 346 & 26.91 \\
\hline Fluoksetin - olanzapin & 148 & 11.52 \\
\hline Fluoksetin - seroquel & 108 & 8.40 \\
\hline Sertralin - klozapin & 59 & 4.59 \\
\hline Fluoksetin - flufenazin & 43 & 3.34 \\
\hline Sertralin - risperidon & 40 & 3.11 \\
\hline Fluoksetin - trifluoperazine & 37 & 2.88 \\
\hline Fluoksetin - klorpromazin & 23 & 1.79 \\
\hline Fluoksetin - aripiprazol & 17 & 1.32 \\
\hline Fluoksetin - donepezil & 12 & 0.93 \\
\hline Fluoksetin - haloperidol & 10 & 0.78 \\
\hline Amitriptilin - risperidon & 5 & 0.39 \\
\hline Amitriptilin - klozapin & 3 & 0.23 \\
\hline Amitriptilin - trifluoperazin & 3 & 0.23 \\
\hline Fluoksetin - amitriptilin & 3 & 0.23 \\
\hline Escitalopram - klozapin & 2 & 0.16 \\
\hline Escitalopram - risperidon & 2 & 0.16 \\
\hline Fluoksetin - escitalopram & 2 & 0.16 \\
\hline Sertralin - donepezil & 2 & 0.16 \\
\hline Amitriptilin - haloperidol & 1 & 0.08 \\
\hline Escitalopram - seroquel & 1 & 0.08 \\
\hline Fluoksetin - ketokonazol & 1 & 0.08 \\
\hline Sertralin - escitalopram & 1 & 0.08 \\
\hline Sertralin - ibuprofen & 1 & 0.08 \\
\hline Interaksi Moderat & 34 & 2.64 \\
\hline Fluoksetin - klobazam & 11 & 0.86 \\
\hline Sertralin - flufenazin & 8 & 0.62 \\
\hline Fluoksetin - alprazolam & 7 & 0.54 \\
\hline Sertralin - alprazolam & 7 & 0.54 \\
\hline Fluoksetin - fenitoin & 1 & 0.08 \\
\hline Interaksi Minor & 6 & 0.47 \\
\hline Fluoksetin - diazepam & 6 & 0.47 \\
\hline Interaksi Tidak Diketahui & $\mathbf{0}$ & $\mathbf{0}$ \\
\hline Total & 1286 & 100 \\
\hline
\end{tabular}


Tabel 5. Hubungan interaksi obat dengan berbagai faktor

\begin{tabular}{llll}
\hline Faktor & Jumlah $(\mathbf{N})$ & Nilai $\mathbf{p}$ & Kesimpulan \\
\hline Jenis Kelamin & 2100 & $0.184\left(\right.$ Continuity Correction $\left.^{b}\right)$ & Tidak ada hubungan \\
Usia & 2100 & $0.768($ Pearson Chi-Square $)$ & Tidak ada hubungan \\
Jumlah obat & 743 & $0.000($ Pearson Chi-Square $)$ & Ada hubungan \\
\hline
\end{tabular}

\section{KESIMPULAN}

Jenis obat antidepresan yang paling banyak diresepkan pada pasien skizofrenia BPJS rawat jalan di RSJ Dr. Soeharto Heerdjan tahun 2016 adalah SSRI. Kombinasi fluoksetin dengan triheksifenidil merupakan kombinasi yang paling sering diresepkan. Sedangkan kombinasi fluoksetin dan risperidon merupakan yang paling banyak terjadi. Tingkat keparahan interaksi obat yang paling banyak terjadi yaitu mayor sebanyak $96,89 \%$ kasus.

\section{UCAPAN TERIMA KASIH}

Ucapan terima kasih kepada pihak yang telah membantu penelitian terutama karyawan instalasi Rumah Sakit Jiwa Dr.Soeharto Heerdjan, Jakarta.

\section{DAFTAR ACUAN}

Amir, N. (2015). Buku ajar psikiatri Edisi ke-2. Jakarta: Balai Penerbit Fakultas Kedokteran Universitas Indonesia.

Brown, C.H. (2008). Psychotropic disorders : Overview of drug-drug interactions with SSRIs. US Pharm. 33(1), 3-19

Churi, S., Nag, K.A., Umesh, M. (2011). Assesment of drug-drug interactions in hospitalised patients in India. Asian Journal of Pharmaceutical and Clinical Research. 4(1), 63.

Dasopang, E.S., Harahap, U., Lindarto, D. (2015). Jumlah obat dan interaksi obat pasien usia lanjut rawat jalan dengan penyakit metabolik. Jurnal Farmasi Klinik Indonesia.

Fitriana, I., Mutmainah, N. (2015). Potensi interaksi obat antidepresan di rumah sakit jiwa " $X$ " Jawa Tengah Periode Januari-September 2015. Surakarta : Universitas Muhammadiyah Surakarta.

Kementerian Kesehatan RI. (2013). Riset Kesehatan Dasar. Badan Penelitian dan Pengembangan Kesehatan Kementrian Kesehatan RI. Jakarta.

Katona, C., Cooper, C., Mary, R. (2012). At a Glance Psikiatri. Ahli bahasa: Asri Dwi Rachmawati. Jakarta: Erlangga.
Kementerian Kesehatan RI. (2016). Peran keluarga dukung kesehatan jiwa masyarakat. 14 September 2018. Diambil dari http://www.depkes.go.id/article/ print/16100700005/peran-keluarga-dukung-kesehatanjiwa-masyarakat.html

Moore, T.A., Buchanan, R.W., Buckley, P.F., Chiles, J.A., Conley, R.R., Crismon, M.L., et al. (2007). The Texas medication algorithm project antipsychotic algorithm for schizophrenia. Journal of Clinical Psychiatry 68, 1752 -1762 .

Redayani, P. (2015). Buku ajar psikiatri Edisi ke-2. Jakarta: Balai Penerbit Fakultas Kedokteran Universitas Indonesia.

Rianti, I., Octaviany, A.F., Kinanti, S. (2015). Analisis efektivitas terapi dan biaya antara haloperidol kombinasi dengan risperidon kombinasi pada terapi skizofrenia fase akut. Yogyakarta : Universitas Muhammadiyah Yogyakarta.

Rossi, A., Barraco, A., Donda, P. (2004). Fluoxetine: a review on evidence based medicine. Ann Gen Hosp Psychiatry;3:2 .

Sari, D.P. (2015). Interaksi obat antipsikotik pada pengobatan pasien skizofrenia rawat jalan di RSUP H.Adam Malik Medan [Skripsi]. Medan : USU.

Spina, E., Avenoso, A., Scordo, M.G., Ancione, M., Gatti , G., et al. (2002). Inhibition of risperidone metabolism by fluoxetine in patients with schizophrenia: a clinically relevant pharmacokinetic drug interaction. J Clin Psychopharmacol; 22(4):419-23.

Truven Health Analytics. (2013). Drug Interactions. Diambil dari http://www.micromedexsolutions.com/ micromedex2/4.34.0/WebHelp/MICROMEDEX_2. $\mathrm{htm} \#$ Tools/Interactions/Drug_Interactions_severity_ definitions.htm

Mao,Ye-Meng.,Zhang, Ming-Dao. (2015). Augmentation with antidepressants in schizophrenia treatment: benefit or risk. Diambil dari: https://www.ncbi.nlm.nih.gov/ pmc/articles/PMC4370910/

Wagner, K.D. (2015). Antidepressants: Risk vs Benefit in 
Depression. Diambil dari http://www.psychiatrictimes. com/geriatric-psychiatry/antidepressants-risk-vsbenefit-depression

Wells, B.G., DiPiro, J.T., Schwinghammer, T.L., \& Dipiro, C.V. (2015). Pharmacotherapy Handbook (9 ed.). United States : McGraw-Hill Education.

World Health Organization. (2016). Schizophrenia. Agustus 20, 2017. Diambil dari: http://www.who.int/ mental_health/management/schizophrenia/en/ 